\title{
Conhecimentos sobre o Lazer nos Cursos de Graduação em Turismo de Minas Gerais $^{1}$
}

\section{Knowledge about Leisure in Undergraduate Courses in Tourism in Minas Gerais, Brazil}

\author{
Christianne Gomes ${ }^{2}$ \\ Alicia Maricel Oliveira Ramos ${ }^{3}$ \\ Hilton Fabiano Boaventura Serejo ${ }^{4}$
}

\begin{abstract}
Resumo
Síntese dos resultados da pesquisa que objetivou diagnosticar/analisar os conhecimentos desenvolvidos sobre o Lazer nos cursos de Graduação em Turismo de Minas Gerais. A metodologia envolveu pesquisa bibliográfica, análise documental e entrevistas com 24 coordenadores e 21 docentes vinculados a 25 instituições. Os resultados evidenciaram que para todos os entrevistados o lazer e o turismo estão interligados. Constatou-se uma ênfase no ensino, através de disciplinas, com poucas ações relacionadas à pesquisa e à extensão. Foi possível perceber a existência de uma confusão conceitual envolvendo os termos "lazer" e "recreação" por parte de alguns entrevistados. Observa-se a importância de superar a visão instrumental de lazer que tem caracterizado as práticas pedagógicas no contexto dos cursos pesquisados, tendo em vista alcançar uma formação no Turismo mais crítica e reflexiva.
\end{abstract}

Palavras-chave: Turismo; Lazer; Graduação; Minas Gerais.

\begin{abstract}
Summary of the results of the research which aimed to diagnoselanalyze the knowledge developed on Leisure in Tourism Undergraduate courses in Minas Gerais, Brazil. The methodology included literature review, analysis of documents and interviews with 24 coordinators and 21 professors from 25 institutions. The results showed that for all respondents, leisure and tourism are interconnected. It was found an emphasis on teaching, through the disciplines, with a few actions related to research and extension. It was possible

\footnotetext{
${ }^{1}$ Pesquisa realizada com o apoio da Fundação de Amparo à Pesquisa do Estado de Minas Gerais (FapemigPPM) e do Conselho Nacional de Desenvolvimento Científico e Tecnológico-CNPq no período 2008-2010.

${ }^{2}$ Doutora em Educação. Docente da Universidade Federal de Minas Gerais; Pesquisadora da Fundação de Amparo à Pesquisa de Minas Gerais (FAPEMIG/PPM II-IV). Líder do Grupo de Pesquisa Otium: Lazer, Brasil \& América Latina. E-mail: chrislucegomes@gmail.com

${ }^{3}$ Bacharel em Turismo pela UFMG e Mestranda em Lazer pela mesma universidade. Membro do Grupo OtiumLazer, Brasil \& América Latina. E-mail: aliciamaricel@gmail.com

${ }^{4}$ Mestre em Educação pela Pontifícia Universidade Católica de Minas Gerais; Especialista em Lazer pela Universidade Federal de Minas Gerais e Especialista em Gestão do Turismo e Meio Ambiente pelo Unicentro Newton Paiva. Docente da Universidade dos Vales do Jequitinhonha e Mucuri - UFVJM. E-mail: hiltonserejo@uol.com.br
} 
to perceive the existence of a conceptual confusion between the terms "leisure" and "recreation" by some respondents. It can be noticed the importance of overcoming the instrumental view of leisure which has characterized the pedagogical practices in the context of the courses surveyed, in order to achieve a more critical and reflective education in Tourism.

Keywords: Tourism; Leisure; Undergraduate Courses; Minas Gerais/Brazil.

\section{Introdução}

Nos últimos anos observou-se um expressivo crescimento dos cursos de Graduação em Turismo no Brasil. Até a segunda metade da década de 1990 apenas uma universidade oferecia formação de nível superior nessa área em Minas Gerais, mas, em poucos anos ocorreu a criação de vários cursos somente neste Estado: seis deles (11,33\%) ministrados por instituições públicas e 47 (88,67\%) por instituições particulares.

Em 2008 foi possível constatar que vários Cursos criados há poucos anos já se encontravam em processo de fechamento, em consequência da dificuldade de muitas instituições formarem turmas com o número mínimo de alunos. Este problema não foi verificado nas instituições públicas, ocorrendo apenas nas particulares. A expressiva retração dos cursos de Turismo já era esperada e está acontecendo em todo o Brasil, pois, em menos de uma única década foram abertos mais de 700 novos cursos no país.

Os aspectos econômicos do turismo são relevantes e explicam, em parte, a rápida e vulnerável expansão dos cursos de Graduação nessa área. Porém, apesar de ser fundamental, a abordagem econômica não é suficiente para compreendermos as complexidades do turismo. Como destacam Gastal e Moesch (2007, p.11), o turismo envolve processos de “estranhamento", ou seja, em seus deslocamentos o turista pode vivenciar processos de mobilização subjetiva ao se defrontar com o novo e com o inesperado. Tudo isso o levaria "a parar e a re-olhar, a repensar, a reavaliar, a ressignificar não só a situação, o ambiente, as práticas vivenciadas naquele momento e naquele lugar, mas muitas das experiências passadas".

Neste sentido, o turismo é um fenômeno humano e uma possibilidade de lazer, caracterizado pelo (re)conhecimento de um lugar extra-ordinário, no qual são estabelecidas as mais variadas 
relações (sociais, econômicas, históricas, políticas, ambientais, culturais, afetivas etc.) em determinado tempo/espaço. Esta compreensão coloca em evidência a necessidade de construir outros referenciais para o turismo e os estudos sobre o lazer podem colaborar com este processo.

O lazer é aqui compreendido como uma dimensão da cultura. Neste sentido, o lazer é caracterizado pela vivência lúdica de manifestações culturais no tempo/espaço social. Constituído conforme as peculiaridades do contexto histórico e sociocultural no qual é desenvolvido, o lazer implica "produção" de cultura — no sentido da reprodução, construção e transformação de práticas culturais vivenciadas ludicamente por pessoas, grupos, sociedades e instituições. Essas ações são construídas em um tempo/espaço social, dialogam e sofrem interferências das demais esferas da vida em sociedade e nos permitem ressignificar, simbólica e continuamente, a cultura (GOMES, 2008; 2010).

Pensar o lazer nessa perspectiva não significa desconsiderar a possibilidade de que ele também pode constituir uma estratégia de manipulação e controle social. Além disso, o sentido que muitas vezes é a ele atribuído está relacionado à sua consideração como algo nãosério, válvula de escape, fonte de consumo de bens/serviços e meio compensador de frustrações advindas dos problemas gerados em nossa sociedade, visões que necessitam ser revistas.

As manifestações culturais que constituem o lazer são práticas sociais vivenciadas como desfrute e como fruição da cultura, tais como a festa, a dança, o jogo, a brincadeira, o teatro, a música, a pintura, o desenho, a escultura, o artesanato, a literatura, a poesia, o espetáculo, o passeio, a viagem e as diversas práticas corporais, entre incontáveis possibilidades. Essas e outras manifestações detêm significados singulares para os sujeitos que as vivenciam ludicamente em um determinado tempo/espaço social. As manifestações culturais vivenciadas ludicamente são, assim, práticas que integram a cultura de cada povo e podem assumir múltiplos significados: ao serem concretizadas em um determinado tempo/espaço social, ao dialogarem com um determinado contexto e, também, ao assumirem um papel peculiar para os sujeitos, para os grupos sociais, para as instituições e para a sociedade que as vivenciam histórica, social e culturalmente (GOMES, 2010).

Assim, esta pesquisa teve como objetivo geral diagnosticar e analisar os conhecimentos 
desenvolvidos sobre o Lazer nos cursos de Graduação em Turismo de Minas Gerais. Para alcançar esta meta mais ampla, teve como objetivos específicos: (a) verificar como a temática do lazer é tratada na legislação nacional que orienta os currículos dos cursos de graduação em Turismo no Brasil; (b) discutir os entendimentos de lazer dos coordenadores e dos professores envolvidos com atividades curriculares relacionadas ao lazer nos cursos pesquisados; (c) verificar como esses docentes compreendem os vínculos estabelecidos entre o lazer e o turismo e (d) analisar de que maneira o lazer é trabalhado nesses cursos de Graduação, considerando as atividades de ensino, de pesquisa e de extensão.

\section{Metodologia}

A pesquisa realizada seguiu os referenciais da abordagem qualitativa. Inicialmente, conhecimentos foram sistematizados por meio de uma pesquisa bibliográfica, desenvolvida no decorrer de todo o estudo, procurando abranger as temáticas centrais: lazer e turismo. Para isso, foi realizado um levantamento bibliográfico que compreendeu textos e publicações (livros, dissertações, teses, periódicos e artigos científicos), bem como outros tipos de trabalhos ou documentos eletrônicos que pudessem ser utilizados como fonte de estudo ou leitura.

Para enriquecer e complementar o estudo da literatura, foi também realizada uma pesquisa documental, que "consiste na coleta, classificação, seleção e utilização de toda espécie de informações, compreendendo também as técnicas e os métodos que facilitam a sua busca e a sua identificação." (FACHIN, 2006, p.146). A pesquisa documental focalizou as Diretrizes Curriculares Nacionais para os cursos de Graduação em Turismo no Brasil (documento anexado a este relatório), além de considerar projetos, programas de disciplinas e outros documentos obtidos no decorrer do estudo, procurando conhecer suas características e investigar em quais condições específicas foram elaborados.

A investigação envolveu também a realização de entrevistas semi-estruturadas com coordenadores e coordenadoras de cursos de Graduação em Turismo de Minas Gerais, bem como com professores e professoras responsáveis pelo desenvolvimento de atividades acadêmicas relacionadas ao lazer no contexto destes cursos. As 25 instituições investigadas não foram identificadas e o anonimato dos entrevistados foi preservado. Foram colhidos os 
depoimentos de 45 docentes vinculados a 25 instituições (24 coordenadores e 21 professores), de maneira que a amostra final representa aproximadamente $48 \%$ do universo investigado. As Instituições de Ensino Superior (IES) não foram identificadas e o anonimato dos entrevistados foi preservado, sendo os coordenadores e professores indicados na pesquisa, respectivamente, pelos códigos $\mathrm{C} 1, \mathrm{C} 2, \mathrm{C} 3$; P1, P2, P3 e assim sucessivamente.

A análise dos dados foi iniciada após a transcrição das entrevistas. Schlüter (2003, p.111) afirma que a técnica da análise de conteúdo "é utilizada com frequência para o estudo do turismo". Flick (2009) salienta que a análise de conteúdo é um dos procedimentos clássicos para analisar o material textual, podendo ser desenvolvida a partir de diferentes enfoques e dividida em várias etapas. Os resultados obtidos com a pesquisa serão apresentados a seguir.

\section{Resultados}

\subsection{Abordagem da temática do lazer na legislação nacional que orienta os currículos dos} cursos de Graduação em Turismo no Brasil

No contexto em que a criação de cursos de Graduação em Turismo no Brasil aumentou de maneira exponencial, tem-se um importante marco para a educação brasileira: a promulgação da nova Lei de Diretrizes e Bases da Educação Nacional - Lei n ${ }^{\circ}$ 9.394, de 20 de dezembro de 1996. Com a nova LDB, foi deflagrado um significativo processo de mudanças que interferiu em todos os níveis da educação.

Os currículos dos cursos de Graduação em Turismo no Brasil passaram a seguir as novas determinações legais definidas pelo Conselho Nacional de Educação (CNE) por meio da Resolução no 13 , de 24/11/2006, que instituiu as Diretrizes Curriculares Nacionais do Curso de Graduação em Turismo, Bacharelado, a serem observadas pelas Instituições de Educação Superior num prazo máximo de dois anos, a partir de sua instituição. ${ }^{5}$ Este documento foi analisado com o intuito de conhecer a referência estabelecida pelo órgão competente. Procurou-se verificar se a temática do lazer constitui um dos conhecimentos que deve integrar a formação em nível superior na área do turismo e, em caso afirmativo, a partir de quais

5 Os documentos aqui mencionados estão disponíveis na Internet, na íntegra, em: $<$ http://portal.mec.gov.br/index.php?option=com_content\&view=article\&id=12991:diretrizes-curricularescursos-de-graduacao-\&catid=323:orgaos-vinculados $>$ Acesso em: 14 jan. 2010. 
enfoques é abordada. Esta análise pode contribuir para explicar, ao menos em parte, a existência ou não de determinadas formações e/ou ênfases na temática do lazer.

A Resolução CNE 13/2006 especifica em $14 \operatorname{artigos}^{6}$ os elementos estruturais que devem constar no Projeto Pedagógico dos cursos, as competências e habilidades requeridas do profissional turismólogo, os campos de formação, as condições de conclusão e integralização curricular, a obrigatoriedade do estágio supervisionado e as atividades complementares, entre outros elementos.

Neste documento, o termo lazer é citado no parágrafo $2^{\circ}$ do art. $2^{\circ}$, ao explicitar que:

O Projeto Pedagógico do curso de graduação em Turismo poderá admitir Linhas de Formação Específicas, direcionadas para diferentes áreas ocupacionais relacionadas com o turismo, abrangendo os segmentos ecológicos e ambientais, econômicos, culturais, de lazer, de intercâmbio de negócios e promoção de eventos e serviços, para melhor atender as necessidades do perfil profissiográfico que o mercado ou a região exigirem. (BRASIL. MEC. CNE, 2006, p. 2. Grifos nossos)

Verifica-se que o lazer é abordado como um possível "segmento" de atuação no turismo, visando conceber formações que atendam à demanda do mercado por determinado profissional. Esta é uma forma restrita de se considerar o lazer, que é um fenômeno que apresenta vínculos com o turismo e essas interfaces vão além das segmentações determinadas pelo mercado. Certamente, essa compreensão interfere nos saberes a serem adquiridos pelo acadêmico do curso de Graduação em Turismo.

Sobre esse aspecto, alguns elementos como as habilidades e competências esperadas do profissional da área são especificadas formalmente nas Diretrizes. As competências e habilidades requeridas ao bacharel em Turismo, conforme especificado na Resolução 13/2006, não apresentam vínculos sólidos com o lazer. Entre as 19 competências e habilidades relacionadas no documento foram identificadas as palavras "recreativas" e “entretenimento" nos incisos X e XVII. Neles entretanto, a abordagem da temática é superficial e pontual, como pode ser verificado a seguir:

\footnotetext{
${ }^{6} \mathrm{O}$ artigo 12 se repete no documento, que equivocadamente totaliza 13 artigos quando, na realidade, são 14.
} 
X - domínios de técnicas relacionadas com a seleção e avaliação de informações geográficas, históricas, artísticas, esportivas, recreativas e de entretenimento, folclóricas, artesanais, gastronômicas, religiosas, políticas e outros traços culturais, como diversas formas de manifestação da comunidade humana;

$[\ldots]$

XVII - compreensão da complexidade do mundo globalizado e das sociedades pósindustriais, onde os setores de turismo e entretenimento encontram ambientes propícios para se desenvolverem;

(BRASIL. MEC. CNE, 2006, p.2-3)

$\mathrm{O}$ inciso $\mathrm{X}$ do art. $4^{\circ}$ indica uma valorização de aspectos operacionais no trato dos aspectos geográficos, históricos, artísticos, esportivos, recreativos e de entretenimento, entre outros, uma vez que aponta o domínio de técnicas para seleção e avaliação de informações no campo do turismo. O inciso XVII, por sua vez, reforça a visão mercadológica ao mencionar as sociedades pós-industriais como ambiente propício para o desenvolvimento dos setores de turismo e entretenimento.

Para Gomes (2009), competências constituem um conjunto de conhecimentos, atitudes, capacidades e aptidões que habilitam um profissional para vários desempenhos na vida. Adquirir competências não se trata apenas da aquisição de conhecimentos disciplinares ou técnicos. É preciso que o profissional busque constante qualificação, que saiba mobilizar os saberes necessários e desenvolva habilidades para enfrentar os imprevistos que surgem no cotidiano das situações de trabalho. Uma competência representa, em sua visão, "a capacidade de encontrar vários recursos, no momento e de forma adequadas". É notório observar que nenhuma habilidade crítica ou de pesquisa é citada no documento como de importância a se desenvolver no graduando em Turismo. Tampouco é mencionada a importância de se articular ensino, pesquisa e extensão, pois, a ênfase recai nas habilidades técnicas, que estabelecem estreitas relações com a segmentação de mercado que predomina na área do turismo.

Considerando o Turismo como um fenômeno multi/interdisciplinar, o profissional da área necessita desenvolver uma maior capacidade de reflexão para lidar com tal complexidade, com um olhar aprofundado e crítico. Vários autores salientam a necessidade de reflexões mais profundas e críticas na formação profissional no Turismo, sem desprezar a necessidade de se desenvolver as habilidades práticas inerentes à profissão.

Apesar de serem relacionadas, no documento, questões científicas, técnicas, sociais e econômicas, estas parecem servir para entender uma instância considerada maior: o mercado. 
Os saberes acadêmicos que devem integrar os currículos dos cursos de Graduação em Turismo acabam adquirindo um peso menor nas Diretrizes. A habilidade de pesquisa e reflexão sobre a própria atuação e sobre o campo são aspectos essenciais para a formação acadêmica do profissional do Turismo.

Sobre a relação teoria/prática, o documento vai ao encontro da posição de Isayama (2005), ao pontuar que, para que se tenha um processo formativo consistente, é necessário que teoria e prática sejam trabalhados simultaneamente, como elementos indissociáveis. A teoria deve ser pensada, formulada e aplicada a partir da realidade concreta e a prática constitui parte indispensável para o desenvolvimento dos conteúdos teóricos.

Os estudos teórico-práticos sobre o lazer podem trazer reflexões interessantes para se pensar o próprio campo do turismo, uma vez que os dois fenômenos apresentam vários pontos de aproximação, que vão além da segmentação do mercado e atuação prática. Estas atividades incluem diversas noções, entre as quais: projetos de pesquisa, monitoria, iniciação científica, projetos de extensão, módulos temáticos, seminários, simpósios, congressos, conferências e disciplinas cursadas em outras instituições.

O currículo deveria pretender formar profissionais conscientes, críticos e capazes de responder aos objetivos abrangentes da área do turismo. O convite é para o desenvolvimento de um currículo que desenvolva pessoas competentes na prática, mas, que sejam também reflexivas. Para Tribe (2003), o profissional deve ver o turismo da perspectiva das diferentes disciplinas, mas também estender a abordagem do fenômeno para além do foco mercadológico, mais comum, para uma visão antropológica, filosófica, sociológica e ambiental. Seria desejável uma formação de profissionais capazes de relacionar os saberes envolvidos no fenômeno, produzindo novas idéias, novas formas de se compreender e promover o turismo, e não apenas lidar com informações estanques aprendendo a classificálas, hierarquizá-las e comercializá-las. A aproximação com o campo de estudos do lazer poderia contribuir com reflexões sobre o fenômeno turístico, considerando as interfaces entre essas áreas.

\subsection{Entendimentos de lazer de professores e coordenadores}

Foi perguntado aos 45 entrevistados qual era o seu entendimento de lazer. Através das respostas pode-se perceber a existência de compreensões diversificadas entre coordenadores e 
professores, vinculados tanto a IES públicas e privadas, seja de Belo Horizonte ou de cidades do interior de Minas Gerais.

As diferentes compreensões de lazer podem ser decorrentes das formações acadêmicas diversas em nível de Graduação desses profissionais, das variadas Pós-graduações cursadas, das visões sobre o curso ao qual estão vinculados, bem como dos distintos posicionamentos quanto ao mercado de trabalho na área do lazer que se abrem para o bacharel em turismo.

Com a análise das respostas foi verificado que, de forma geral, os professores possuem conhecimentos mais ampliados sobre o lazer do que os coordenadores de curso, constatação que, de certa forma, era esperada. As respostas dos professores ao questionamento sobre o entendimento de lazer foram mais especificas e detalhadas do que aquelas elaboradas pelos coordenadores dos cursos de turismo.

A maior parte dos coordenadores se limitou a dar uma resposta breve sobre o entendimento da temática lazer. Foi possível perceber uma insegurança ao abordar o tema, o que é compreensível uma vez que nenhum destes profissionais se especializou ou dedicou estudos mais aprofundados sobre a área. Alguns coordenadores expressaram, inclusive, dificuldades em diferenciar lazer e turismo.

Sobre esta dificuldade, o depoimento que se segue ilustra o que foi relatado por C8: "Olha, para ser sincero, é uma área que eu visito muito pouco. [...] normalmente, quem trabalha com o lazer é o professor de educação física, não é o turismólogo [...]."

Entre os coordenadores de cursos de Graduação em Turismo vinculados a IES privadas, tanto da capital mineira quanto das cidades do interior do Estado, prevalece a compreensão de que o lazer é um serviço a ser prestado no âmbito do turismo $(\mathrm{C} 2, \mathrm{C} 3, \mathrm{C} 4, \mathrm{C} 5, \mathrm{C} 10, \mathrm{C} 11, \mathrm{C} 12 \mathrm{e}$ C20). Neste ponto de vista o lazer estaria relacionado às atividades recreativas que são realizadas nos eventos e em equipamentos turísticos - como hotéis, resorts e navios - visando a ocupação do tempo livre dos turistas. Este entendimento aproxima-se do conceito de lazer formulado por Dumazedier (1979) e que foi criticada, entre outros aspectos, por restringir o lazer à mera ocupação ou atividade. Entre outros aspectos, este conceito desconsidera as possibilidades de ócio enquanto reflexão, contemplação, relaxamento e/ou descanso.

O relato a seguir exemplifica a visão de um dos coordenadores citados: "Bom, eu não sou 
professor de lazer. O meu entendimento de lazer, no contexto do turismo, é uma lógica ligada à ocupação do tempo, no sentido de absorção de um tempo livre de uma forma ordenada."

Outro aspecto enfatizado pelos coordenadores dos cursos investigados é de que o lazer se relaciona com desligamento da rotina, descontração, divertimento, distração e alegria $(C 2, C 3$, C4, C8, C11, C13, C17, C21 e C24). Por exemplo, C3 destacou que: "O lazer é uma área de estudo que propicia o envolvimento com a parte gerencial de empreendimentos que vão proporcionar entretenimento, descontração, fuga do cotidiano. A gente trabalha em cima disso."

Torna-se necessário explicitar que essas visões de lazer também estiveram presentes nas falas de alguns professores, contudo, com uma recorrência menor.

Os entendimentos de lazer enunciados por vários entrevistados precisam ser repensados. Afinal, a partir de distintas nuanças, concebem o lazer como um simples produto da indústria cultural, como mercadorias geralmente materializadas nas atividades recreativas desenvolvidas no âmbito dos equipamentos turísticos. Além disso, atribuem ao lazer o papel de promover a distração e a fuga do cotidiano, atuando como "válvula de escape" para as tensões do dia-a-dia. O lazer não pode ser pensado apenas como algo que existe para renovar as energias para o trabalho, tampouco ser reduzido a contraponto das obrigações. O lazer é, em sua essência, um fenômeno sociocultural que diz respeito a práticas culturais diversas, as quais são coletivamente produzidas em cada realidade histórico-social.

Outros aspectos relacionados ao entendimento de lazer dos voluntários entrevistados na pesquisa podem ser destacados. Dois professores procuraram embasar suas respostas nos conhecimentos produzidos por autores do chamado campo de estudos sobre o lazer. O professor $\mathrm{P} 11$ afirmou compreender o lazer como um "conjunto de ocupações às quais o individuo pode entregar-se de livre vontade", conforme o conceito elaborado por Dumazedier (1979). Já o professor P14 utilizou a definição elaborada por Marcellino (1987) para expressar sua própria concepção, dizendo que o lazer é a “cultura - compreendida no seu sentido mais amplo - vivenciada (praticada ou fruída) no tempo disponível".

Nenhum coordenador citou uma compreensão de lazer mais elaborada, ou pautada em algum referencial teórico, que pudesse fundamentar seu entendimento, o que pode ser uma evidencia 
de que esses profissionais tiveram pouco (ou nenhum) contato com os estudos sobre o lazer no decorrer de suas formações acadêmicas. Interessante observar que vários coordenadores (14) não conseguiram mencionar nenhum autor que tenha produzido conhecimentos ou publicado algum trabalho sobre a temática do lazer $(\mathrm{C} 1, \mathrm{C} 5, \mathrm{C} 7, \mathrm{C} 8, \mathrm{C} 10, \mathrm{C} 11, \mathrm{C} 12, \mathrm{C} 13$, C14, C17, C20, C21, C22, C23).

Considerando que a temática do lazer integra a formação acadêmica dos cursos de Graduação em Turismo de Minas Gerais, é importante que professores e coordenadores busquem conhecer estudos e reflexões que vêm sendo feitos no campo do lazer, bem como analisar algumas das principais concepções trabalhadas e difundidas neste campo. Este exercício pode contribuir para ampliar e aprofundar os conhecimentos sobre o lazer e instigar novos olhares, mais críticos e reflexivos, sobre este tema.

Alguns professores vinculados as IES públicas e privadas de Belo Horizonte expressaram o entendimento de lazer enquanto uma dimensão da cultura (P1, P3, P5, P6). O professor P6 afirma que lazer é um fenômeno social, histórico e cultural, uma dimensão da vida humana. $\mathrm{O}$ professor P5 afirma que existe ligação do lazer à cultura a qual, sendo dinâmica, sofre mudanças ao longo do tempo. Portanto, no seu ponto de vista, o lazer relaciona-se com alguns elementos considerados básicos: opção (possibilidade de opção do sujeito em vivenciá-la), busca do prazer (interesse em alcançá-lo) e gratuidade (sem o compromisso de ganhar dinheiro). Dois professores vinculados a instituições privadas do interior de Minas Gerais (P14 e P15) também apontaram esse entendimento. No que se relaciona aos coordenadores, apenas um deles (C6), que está vinculado a uma IES pública da capital mineira, compartilhou esta idéia ao dizer que compreende o lazer como "uma experiência humana no tempo livre".

Apesar das diferenças conceituais entre os estudiosos da área é possível verificar uma tendência, entre os autores críticos que vêm produzindo conhecimentos sobre o lazer na realidade brasileira, em compreendê-lo como uma dimensão da cultura. Alguns autores que o observam a partir dessa perspectiva são Alves (2003), Gomes (2008), Gomes e Faria (2005) e Marcellino (1987; 1995), entre outros.

Essa compreensão de lazer embasa a presente investigação, pois, é considerada ampliada e contextualizada. Assumir que o lazer é constituído conforme as peculiaridades do contexto histórico e sociocultural no qual se desenvolve, significa reconhecer que este fenômeno está 
dialogando e sofrendo interferências das demais esferas da vida em sociedade.

Em suma, a partir das informações levantadas e analisadas nesta pesquisa, pode-se perceber a existência de vários entendimentos de lazer. Contudo, nota-se que no contexto da Graduação em Turismo predomina uma compreensão de lazer fortemente ligada ao "uso do tempo livre" e a "atividades recreativas e de entretenimento" em equipamentos turísticos, principalmente no contexto dos cursos desenvolvidos nas IES privadas do interior de Minas Gerais.

Foi também constatada a existência de diferentes concepções de lazer. Quase todos os professores que desenvolvem atividades acadêmicas relacionadas ao lazer nos cursos de Graduação em Turismo de Belo Horizonte compreendem o lazer como uma dimensão da cultura. Esse entendimento, no entanto, não foi observado entre professores das cidades do interior de Minas Gerais.

Considera-se, pois, importante aprofundar conhecimentos sobre a temática do lazer, que apresenta importantes interfaces com o turismo. Relação essa destacada como algo importante por todos os coordenadores e professores, como será discutido no tópico a seguir.

\subsection{Relações constituídas entre o lazer e o turismo}

Ao serem indagados sobre vínculos constituídos entre lazer e turismo, vários entrevistados pontuaram que estes fenômenos estão interligados e consideram que os estudos do lazer estão intimamente relacionados ao turismo. Alguns explicitaram que não compreendem que possa existir um curso de Graduação em Turismo que não desenvolva estudos articulados ao lazer.

A partir das respostas obtidas foi possível perceber que para todos os coordenadores e professores lazer e turismo estão interligados e estabelecem íntima relação, como pode ser verificado nos depoimentos de alguns dos voluntários da pesquisa:

Primeiro tem que compreender que eu considero que o lazer está intimamente relacionado ao turismo, então eu não consigo compreender alguém que se forme em turismo e que não estude lazer. São áreas que estão intimamente relacionadas. Estudou turismo tem que estudar lazer, não tem como. Então dentro da formação tem que ter essa relação direta. (P1).

Não consigo dissociar a palavra lazer da palavra turismo. Eu acho muito importante, eu acho que deveria ter mais coisa de lazer do que tem [...]. (C7) 
Embora a articulação entre turismo e lazer tenha sido uma unanimidade entre os entrevistados, foram utilizados argumentos variados para explicar a ligação entre esses fenômenos.

Alguns entrevistados (C1, C6, C7, C10, C15, C16, C20, P1, P4, P6, P13, P15 e P18) consideram o lazer um campo amplo, no qual o turismo estaria inserido. De acordo com eles, o turismo seria uma das possibilidades de vivenciar o lazer, uma de suas vertentes. Nessa mesma direção, dois professores (P4 e P14) disseram que o turismo é um dos "conteúdos culturais do lazer", compreendendo assim o lazer como um fenômeno maior no qual o turismo está inserido. Alguns relatos evidenciam esta compreensão:

Turismo é lazer de uma certa forma, não importa que tipo de turismo você esteja fazendo, ele sempre deve estar embutido ao lazer. (C7)

O lazer é a base do turismo. Então, pode prestar atenção que o turismo ele só acontece a partir do momento que você segue para o lazer. (C10).

[...] para se fazer turismo pressupõe-se que haja um tempo de lazer. Então o lazer antecede a questão do turismo. (P4)

A compreensão destes entrevistados pode ser associada com as reflexões de alguns autores. Para Camargo (1992), Marcellino (1996), Melo e Alves Júnior (2003), o turismo é um dos "conteúdos culturais do lazer", ou seja, uma das diversas motivações e interesses pelos quais os sujeitos procuram vivenciar o lazer. Marcellino (1996) explica que o turismo pode e deve ser entendido como uma atividade cultural de lazer, uma oportunidade de conhecimento e de enriquecimento das sensibilidades. Melo e Alves Júnior (2003) sugerem que o lazer turístico, além do conhecimento de outras localidades, pode estimular o reconhecimento do próprio espaço onde vive o indivíduo e, assim, combater o esvaziamento dos espaços públicos como lugar de vivência social.

Todavia, opinião contrária foi demonstrada por outros entrevistados $(\mathrm{C} 2, \mathrm{C} 3, \mathrm{C} 4, \mathrm{C} 5, \mathrm{C} 8, \mathrm{C}$, C18, C21, P19) ao afirmarem que o turismo é o campo maior no qual o lazer está inserido. Para esses voluntários o lazer é que estaria "dentro" do turismo sendo, portanto, uma de suas segmentações ou uma motivação para que o turista se desloque, como pode ser verificado nos exemplos que se seguem: 
Existem várias motivações para o turismo, e uma delas é o lazer. (C9)

[...] temos diversos tipos de Turismo [...]. Mas eu acho que a linha forte do turismo passa pelo lazer. A não ser o turismo de saúde. Todos os outros estão ligados de uma maneira ou outra à atividade de lazer. (C8)

Foram identificadas, ainda, outras perspectivas para se compreender as relações entre o lazer e o turismo. Alguns professores (P9 e P12) afirmaram que não há diferenças entre os dois fenômenos ao dizer que "turismo é lazer", tratando-os, portanto, como sinônimos.

Segundo Camargo (2001) o entendimento de turismo e lazer como sinônimos é frequente em diversos segmentos da sociedade. De acordo com o autor, para grande parte da população o conceito de turismo sempre tem uma conotação lúdica que o aproxima do lazer, e as férias representam o tempo livre para vivência tanto do lazer quanto do turismo. Esta é, em geral, uma visão muito difundida no senso comum.

A dificuldade de compreensão sobre esta polêmica questão pode ser justificada pela falta de sistematização de conhecimentos sobre os vínculos entre lazer e turismo. Nota-se que poucos estudos visaram discutir as aproximações, semelhanças e diferenças existentes entre esses fenômenos. São pertinentes as observações de Camargo (2001), que afirma que o campo do lazer deve constituir objeto de conhecimento e vivência imprescindível ao profissional do turismo, tendo em vista a necessidade de uma nova compreensão acerca deste fenômeno. Assim, considera-se que esta interface deve ser tema de reflexões para os profissionais, estudantes e pesquisadores de ambas as áreas.

É importante esclarecer que, do ponto de vista desta pesquisa, o fato de existirem interfaces entre o lazer e o turismo não significa que sejam sinônimos. Este aspecto foi ressaltado por um coordenador (C22) e também por dois professores (P5 e P6), que entendem que lazer e turismo, apesar de possuírem muitos vínculos, são campos diferentes. Nas palavras do professor P5, o lazer "[...] estabelece uma relação muito íntima com o turismo, mas na verdade são dois campos distintos que tem uma interface muito presente."

Como observam Araújo e Isayama (2009), por mais que alguns autores tentem sobrepor ou reduzir um fenômeno ao outro, é necessário entender que lazer e turismo se recortam mutuamente, mas são fenômenos distintos. Alguns entrevistados percebem claramente os 
limites e as interseções entre os campos do lazer e do turismo, entendendo que são áreas distintas, mas interligadas. O professor P2 ilustra essa visão ao dizer que " [...] no fundo é uma diferença muito tênue, [...] eu acho que no fundo [lazer e turismo] são complementares." Mesmo apresentando diferenças e semelhanças - tanto na produção acadêmica quanto na prática cotidiana -, lazer e turismo apresentam fronteiras muito tênues. Embora sejam formulados conceitos distintos para designar o lazer e o turismo, na realidade concreta nem sempre é possível delinear onde um começa e o outro termina. Como pondera Morin (2007, p.72-73), "os conceitos não se definem jamais por suas fronteiras, mas a partir de seu núcleo." Afinal, "as fronteiras são sempre fluidas, são sempre interferentes."

Pelo exposto, apesar das visões dos entrevistados serem divergentes, entende-se nesta pesquisa que lazer e turismo possuem particularidades e apresentam fronteiras tênues. Ambos são construções sociais que podem representar um tempo/espaço de expressão humana, de fruição, espontaneidade, prazer e de recriação de nossas identidades através do contato com novas situações, pessoas, paisagens, sociedades e culturas.

\subsection{Ensino, Pesquisa e Extensão: atividades acadêmicas sobre o lazer}

Dias (2009, p.38) relata que o princípio da indissociabilidade entre ensino, pesquisa e extensão nas universidades foi determinado na Constituição Federal de 1988, juntamente com o princípio da autonomia universitária (didático-científica, administrativa e de gestão financeira e patrimonial). Com essa determinação, ensino, pesquisa e extensão devem possuir igual relevância. De acordo com a Política Nacional de Graduação, tal indissociabilidade não pode ser limitada "nem ao processo de produção do saber novo, nem às práticas de intervenção direta nos processos sociais" (DIAS, 2009, p. 42).

Apesar de nem todas as IES pesquisadas serem "universidades" (não tendo, portanto, que assumir o compromisso de garantir a indissociabilidade entre ensino, pesquisa e extensão), entende-se que a existência de ações de extensão e/ou de pesquisa em uma determinada instituição deve ocorrer de forma integrada ao ensino, complementando-se mutuamente para enriquecer o processo formativo.

Na pesquisa foi identificada a existência de pelo menos uma disciplina sobre a temática do lazer nos cursos de Graduação em Turismo de Minas Gerais investigados. Foi também 
relatado, pelos entrevistados, o desenvolvimento de algumas ações relacionadas ao lazer no âmbito da extensão e da pesquisa. Foi constatado, no entanto, uma ênfase muito maior no ensino, através de disciplinas, do que na pesquisa e nas ações de extensão.

De um modo geral, os conhecimentos abordados nessas disciplinas incluem a discussão de vários temas, sendo verificada uma grande diversidade de assuntos abordados sobre o lazer. Considerando os conteúdos que os docentes entrevistados afirmaram trabalhar nas disciplinas sobre o lazer da Graduação em Turismo, os temas mais enfatizados na coleta de dados foram: Lazer e educação (P1, P3, P6, P8, P21); Conceitos de lazer (todos os professores); Sociologia do lazer; Formação elou atuação profissional (P5, P6, P16, P20); Lazer e cultura (P1, P3, P5, P6, P21); Conteúdos culturais do lazer (P1, P3, P7, P21); Ludicidade, brincar, brincadeiras, manifestações folclóricas, brinquedoteca (P6, P7, P16); Jogos cooperativos (P8, P20); Recreação e animação turística em hotéis e outros espaços (C10, C11); Lazer e políticas públicas (P5, P6); Espaços e equipamentos de lazer (P6 e P11); Lazer e eventos (P17, P20, C21); Animação cultural (P1, P3, P5, P19).

No decorrer das entrevistas alguns professores mencionaram que os alunos têm expectativas por aulas práticas, considerando as possibilidades que geralmente caracterizam a visão "tradicional" de recreação. Werneck e Isayama (2001) ponderam que é comum haver expectativas e até mesmo uma cobrança de que as experiências ligadas ao lazer, nos currículos, proporcionem atividades práticas e prazerosas que possam descontrair os alunos, mesmo que sejam desconectadas da realidade social e dos conhecimentos construídos em uma determinada área de formação acadêmica e profissional. Entretanto, os autores observam que as praticas precisam ser refletidas, fundamentadas e articuladas com fundamentos teóricos consistentes e críticos.

Alguns estudos (ISAYAMA, 2002; ALVES et al., 2005; BERNARDINO, ISAYAMA, 2006) indicam que a visão técnica e tradicional de recreação predomina em diferentes cursos e disciplinas realizados no país. O entrevistado P6 afirmou que, no momento de sua contratação docente, a expectativa de uma atuação pautada nesta visão instrumental foi salientada nos primeiros contatos com a coordenação. A presente pesquisa constatou que, embora esta visão ainda prevaleça, em alguns cursos há um grande esforço para trabalhar o lazer de forma mais crítica. Alguns docentes, como P1, P2, P3, P6 e P21, disseram abordar o lazer para além da 
visão tradicional de recreação, comprometendo-se em superar a ênfase na parte técnica, operacional e muitas vezes descontextualizada.

Alguns entrevistados (C2, C3, C8, P6 e P18) também destacaram que os conteúdos a serem trabalhados pelo lazer no contexto dos cursos de Graduação em Turismo precisam ser contextualizados nesta área. Por ser um campo multi/interdisciplinar, o lazer possibilita a sistematização de saberes interdisciplinares e multifacetados (ALVES, 2003; GOMES, 2008; ISAYAMA, 2002; MARCELLINO, 1995; ISAYAMA, 2002). Assim, a qualificação fica muito mais sólida e consistente quando as particularidades de cada curso são levadas em consideração, de maneira que vários profissionais possam colaborar com o avanço de saberes e de experiências sobre o lazer em nossa realidade a partir da área em que se formaram.

Tais reflexões indicam ser essencial repensar a sistemática de recreação arraigada culturalmente em nosso contexto. Deve-se ficar claro que o objetivo de uma graduação não é somente oferecer informações sobre técnicas avançadas, processos novos e novas conquistas científicas e tecnológicas. É mais que isso, é qualificar os acadêmicos para que sejam capazes de desenvolver o pensamento autônomo, a independência, a crítica e o poder criador no campo de sua especialidade, sem perder de vista o quadro humano em que está inserido. Por essa razão, é essencial que a visão instrumentalizada que caracteriza a "recreação" e a "animação turística" sejam repensadas, tendo em vista construir com os alunos, no decorrer de seu processo de formação acadêmica, "práticas de lazer refletidas", como bem afirmou P5.

A discussão teórico-metodológica sobre pesquisa em lazer e turismo também se faz necessária. $\mathrm{Na}$ área do Turismo é possível constatar uma intensa reprodução de conhecimentos e, de acordo com Barretto e Santos (2005, p. 363), "reiteram-se conhecimentos porque não se faz pesquisa para gerar novos." Por essa razão, consideramos que é na produção do "saber" e na sua socialização que as IES devem focalizar seus esforços, atuando como um centro de pesquisa, ensino e extensão, caracterizando-se assim como um local privilegiado para a criação do conhecimento e sua disseminação.

Muitos professores, tanto de Belo Horizonte quanto do interior do Estado, apontaram a carência de projetos de extensão e de pesquisas relacionadas diretamente ao lazer. Entre as IES investigadas, poucas desenvolvem trabalhos de pesquisa apesar de que, como já explicitado, isso deve ser incentivado através de uma política institucional. Uma política que 
incentive a produção do saber, mas uma produção que não fique apegada exclusivamente a dogmas ou aos interesses do mercado.

Docentes de duas das 25 IES pesquisadas (uma pública e a outra privada) disseram já ter realizado pesquisas sobre a temática do lazer e outras duas afirmaram que existem pesquisas em andamento. A pesquisa já concluída na IES particular, apesar de não ter ofertado nenhuma bolsa de iniciação científica, foi financiada pela própria instituição, que possui um Centro de Pesquisas. As pesquisas já concluídas na IES pública tiveram o apoio de financiamentos e bolsas. Foi também relatado que não existe, na maioria das IES investigadas, algum tipo de incentivo específico para o desenvolvimento de pesquisas sobre o lazer.

O professor P7 reconhece que há incentivos para o desenvolvimento de pesquisas, porém a dificuldade para efetivação dos projetos está na pouca adesão dos alunos (motivada principalmente pelo fato de trabalharem). Este fato precisa ser cuidadosamente considerado, pois, apesar das dificuldades vivenciadas pelos estudantes trabalhadores, o contato com a pesquisa é fundamental para uma formação mais crítica da realidade. Através dela, o profissional em formação poderá desenvolver projetos de acordo com as metodologias mais adequadas, adquirindo maiores habilidades de escrita, sistematização de conhecimentos e análise crítica. O coordenador $\mathrm{C} 19$, por sua vez, ressalta que a baixa titulação dos professores é um obstáculo que dificulta o desenvolvimento de pesquisas. $\mathrm{O}$ atual processo de fechamento de vários cursos reflete na situação das pesquisas. Como relatado por P6, com o fechamento do curso, coloca-se em dúvida a continuidade do apoio aos projetos de pesquisa.

Para explicar o número reduzido de pesquisas realizadas, pode-se considerar o interesse de cada instituição em desenvolver pesquisas. Como exemplo, alguns professores citaram a visão instrumental predominante nas IES's em que atuam. A pouca ênfase na pesquisa também pode ser um reflexo das Diretrizes Curriculares Nacionais para os Cursos de Graduação em Turismo, que não estimulam essa ação. Além de projetos de pesquisa, foram citados pelos entrevistados cinco grupos de estudos vinculados à temática do lazer.

Assim como a pesquisa, a extensão universitária possui importância fundamental na formação acadêmica. Afinal, “a extensão é a consolidação da pesquisa. A pesquisa deve ter um cunho social, porquanto construir conhecimento deve servir a sociedade de alguma forma, em algum momento, caso contrário não faz sentido.” (VALENTIM, 2007, p. 6) 
Foram mencionados pelos entrevistados 21 projetos de extensão vinculados ao lazer nos cursos de Graduação em Turismo. Pelos depoimentos dos docentes, foi possível perceber que o lazer é trabalhado de diversas formas nas atividades de extensão dos cursos de Turismo. Os projetos visam desenvolver atividades lúdicas e de reflexão com a comunidade; a organização da visitação de espaço turístico; ou a realização de vivências do lazer em espaços lúdicos (brinquedoteca). Uma questão interessante é que os projetos de extensão contam com a participação de graduandos de diferentes áreas, indicando que a multidisciplinaridade é uma realidade. Contudo, o processo de fechamento dos cursos de Graduação também se reflete nos projetos de extensão, resultando na migração das iniciativas ligadas ao lazer dos cursos de Turismo para os cursos de Educação Física.

Em suma, foi constatado que o desenvolvimento de pesquisas ainda é limitado. O incentivo a novas pesquisas e o apoio por parte das instituições são reduzidos. Além disso, a baixa qualificação dos professores da área do Turismo ainda dificulta a obtenção de apoio de entidades como o CNPq e a FAPEMIG. Tudo isso reflete numa menor diversificação das estratégias de ensino, muitas vezes limitando o aprendizado à sala de aula. Em termos de ensino, de um modo geral, a carga horária dedicada ao lazer é bastante reduzida, sendo que muitas IES ofertam apenas uma disciplina. Os conteúdos tratados variam entre as instituições, mas as discussões sobre os conceitos para o lazer e outros termos relacionados estão presentes na maioria das disciplinas.

Apesar desta realidade entre as IES pesquisadas, observa-se que há um esforço por parte das universidades em desenvolver ações de extensão e de pesquisa junto ao ensino, demonstrando a tentativa de efetivar o tripé ensino-pesquisa-extensão. Dessa forma, vê-se a participação de alunos de diferentes formações como um fator interessante para os projetos de extensão, que pode ser levado também às ações de ensino e pesquisa. Acredita-se que o fortalecimento de projetos interdisciplinares possa contribuir a uma formação mais contextualizada e critica, consolidada na percepção da realidade social e dos desafios desses profissionais.

\section{Conclusão}

A pesquisa documental constatou que, no Brasil, o curso de Turismo foi incluído na área de Administração. Pode-se considerar que este fato tenha contribuído para uma maior ênfase das 
Diretrizes Curriculares nesta área. Outro aspecto a ser ressaltado refere-se ao fato de que o lazer é citado neste documento apenas uma vez, e da maneira como foi abordado fica restrito a um segmento do turismo. O documento apresenta uma ênfase nos aspectos técnicos e operacionais, que nesta pesquisa são considerados insuficientes para garantir uma formação interdisciplinar, crítica, sólida e consistente (BRASIL, 2006).

Além disso, no documento são mencionados os termos "entretenimento" e "informações recreativas", que também não são suficientes para indicar em qual abordagem são considerados, tampouco podem ser considerados sinônimos de lazer. Foi identificada uma possibilidade para que a temática do lazer seja aprofundada nas "Atividades Complementares" da formação do bacharel em Turismo, mas o documento não indica possibilidades para isso (BRASIL, 2006). Percebeu-se que as Diretrizes curriculares nacionais não incentivam a realização de pesquisas, uma vez que nem mesmo as monografias de conclusão dos cursos são obrigatórias na Graduação em Turismo - uma área que necessita avançar os seus conhecimentos, e a pesquisa é uma condição sine qua non para isso.

Sobre os entendimentos de lazer dos coordenadores e dos professores envolvidos com as atividades curriculares relacionadas ao lazer nos cursos de Graduação pesquisados, os resultados das entrevistas evidenciaram a existência de variadas compreensões, o que também foi verificado na revisão da literatura (DUMAZEDIER, 1979; MARCELLINO, 1987; GOMES, 2008). Predomina uma compreensão de lazer fortemente ligada ao "uso do tempo livre" e a "atividades recreativas e de entretenimento" em equipamentos turísticos. Esse entendimento está presente principalmente no contexto dos cursos de Turismo desenvolvidos nas universidades privadas do interior de Minas Gerais.

Foi também constatada a existência de diferentes concepções de lazer. Os autores que fundamentam as diferentes compreensões identificadas foram: Marcellino (1996); Dumazedier (1979), Gomes (2004), Werneck (2003), Melo e Alves Júnior (2003), dentre outros.

Em Belo Horizonte, quase todos os professores que desenvolvem atividades acadêmicas relacionadas ao lazer nos cursos pesquisados o compreendem como uma dimensão da cultura. Esse entendimento, no entanto, não foi observado entre professores das cidades do interior de Minas Gerais. Considerando as diferenças entre a recreação e o lazer, as entrevistas 
demonstraram que este assunto não é muito claro para todos. Foi possível perceber nas respostas dadas por alguns dos coordenadores e professores a existência de uma certa confusão entre os termos "lazer", "recreação" e "entretenimento", termos que apareceram na análise documental, no entanto com uma visão superficial e restrita. No decorrer das entrevistas realizadas, essas palavras foram muitas vezes empregadas como sinônimos.

No que se refere às relações constituídas entre o lazer e o turismo, na visão dos entrevistados essa questão evidenciou diferentes interpretações. Mesmo apresentando diferenças e semelhanças, lazer e turismo apresentam fronteiras muito tênues, seja na produção acadêmica sobre o tema, seja na prática cotidiana. Apesar das visões dos entrevistados serem muitas vezes divergentes, entende-se nesta pesquisa que lazer e turismo possuem particularidades e apresentam fronteiras muito próximas. Ambos são construções sociais que podem representar um tempo/espaço de expressão humana, de fruição, espontaneidade, prazer e de recriação de nossas identidades através do contato com novas situações, pessoas, paisagens, sociedades e culturas.

Em Belo Horizonte, todos os cursos de Graduação em Turismo investigados ofertam/ofertavam uma disciplina sobre o lazer, sendo que dois deles contam com duas disciplinas em seus currículos. No interior do Estado, três cursos ofertam duas disciplinas e uma instituição oferta três, mas o que é mais recorrente é o desenvolvimento de apenas uma disciplina sobre o lazer na Graduação em Turismo.

De um modo geral, os conhecimentos abordados nessas disciplinas incluem a discussão de vários temas, sendo verificada uma grande diversidade nos assuntos abordados sobre o lazer nas instituições investigadas. Considerando os conteúdos que os docentes entrevistados afirmaram trabalhar nas disciplinas sobre o lazer da Graduação em Turismo, os temas mais enfatizados na coleta de dados foram: Lazer e educação; Conceitos de lazer; Sociologia do lazer; Formação e/ou atuação profissional; Lazer e cultura; Conteúdos culturais do lazer; Ludicidade, brincar, brincadeiras, manifestações folclóricas, brinquedoteca; Jogos cooperativos; Recreação e animação turística em hotéis e outros espaços; Lazer e políticas públicas; Espaços e equipamentos de lazer; Lazer e eventos e Animação cultural. 
Alguns entrevistados destacaram que os conteúdos a serem trabalhados pelo lazer nos cursos de Graduação em Turismo precisam ser contextualizados nesta área. Alguns professores enfatizaram, ainda, a necessidade de considerar as particularidades locais e da região.

As metodologias utilizadas para trabalhar os conhecimentos sobre o lazer, conforme mencionado pelos professores, são semelhantes. Os recursos didáticos mais empregados são aulas expositivas, seminários e discussões. Além disso, propõem leitura de textos, exibição de filmes, visitas técnicas, oficinas e vivências, dinâmicas em grupo, aulas práticas e execução de projetos. Vários entrevistados afirmaram que, nas disciplinas sob sua responsabilidade, a carga horária é compartilhada entre aulas teóricas e aulas práticas.

Foi constatada a escassez de pesquisas sobre o lazer (e também sobre o turismo). Poucas instituições desenvolvem trabalhos de pesquisa, pois, têm custo significativo e retorno a médio/longo prazo. No Brasil, em geral são as universidades públicas e algumas particulares que valorizam a pesquisa e a formação continuada de seu corpo docente, para que seus professores desempenhem o papel de pesquisadores e, assim, tenham condições de trabalho adequadas para que possam obter financiamento para as suas investigações.

Além de alguns projetos de pesquisa, foram citados pelos entrevistados cinco grupos de estudos vinculados à temática do lazer. Pelos depoimentos dos docentes, foi possível perceber que o lazer é trabalhado de diversas formas nas atividades dos cursos de Turismo junto as comunidades.

Pelo exposto, esta investigação evidenciou a importância de repensar a visão instrumentalizada que caracteriza a "recreação" e a "animação turística", tendo em vista sistematizar práticas pedagógicas e construir conhecimentos sobre o lazer contextualizados, consistentes e críticos. É essencial superar a visão técnica que permeia a formação/ação do bacharel em Turismo, aprofundar conhecimentos multi/interdisciplinares sobre o lazer na Graduação e ampliar as pesquisas neste âmbito, buscando conferir uma maior consistência teórica e crítica à formação e atuação profissional nesta área.

Destaca-se a importância de que professores e coordenadores coloquem-se a par dos estudos e reflexões que vêm sendo feitos no campo do lazer no Brasil e em outros países, tendo em vista que essa temática integra a formação acadêmica dos futuros Bacharéis em Turismo e oferece possibilidades para a inserção do profissional nesse campo. 
Sugere-se que professores e coordenadores busquem aprofundar, atualizar e ampliar seus conhecimentos sobre o lazer e sobre o turismo, o que possibilitará o desenvolvimento de novos olhares, mais críticos e reflexivos, sobre a temática.

\section{Referências}

ALVES, V.F.N. et al. 2005. Lazer, lúdico e educação. Brasília: SESI/DN. . 2003. Uma leitura antropológica sobre a educação física e o lazer. In: WERNECK, C. L. G.; ISAYAMA, H. F. (Org.). Lazer, recreação e educação física. Belo Horizonte: Autêntica. p. 83-114.

ARAÚJO, Marina; ISAYAMA, Hélder F. 2009. As fronteiras entre turismo e lazer. Anais. X Seminário O Lazer em Debate. Belo Horizonte, UFMG/DEF/CELAR.

BARRETTO, M; SANTOS, R. J. 2005. Fazer científico em turismo no Brasil e seu reflexo nas publicações. Turismo: visão e ação. Itajaí, v 7, n.2.

BERNARDINO, Cristina R; ISAYAMA, Hélder F. 2006. Lazer e Turismo: Análise de Currículos de Cursos de Graduação em Turismo de Minas Gerais. Licere. Belo Horizonte, vol. 9, n.2, p.8-23.

BRASIL. 1988. Constituição da República Federativa do Brasil. São Paulo: Tecnoprint.

BRASIL. MEC. 2006. Conselho Nacional de Educação. Diretrizes Curriculares Nacionais do Curso de Graduação em Turismo. Resolução CNE/CES no 13, de 24 de novembro de 2006. Disponível em: $<$ http://portal.mec.gov.br/cne/arquivos/pdf/rces13_06.pdf> Acesso: 09/12/2009.

CAMARGO, L. O. L. 1992. O que é lazer? 3.ed. São Paulo: Brasiliense.

2001. Sociologia do Lazer. In: ANSARAH, M. G. R. (Org.). Turismo: Como aprender, como ensinar. 2 ed. São Paulo: Editora SENAC São Paulo.

DIAS, Ana Maria Iorio. 2009. Discutindo caminhos para a indissociabilidade entre ensino, pesquisa e extensão. Revista Brasileira de Docência, Ensino e Pesquisa em Educação Física - Vol. 1, n. 1, p.3752. Disponível em: $<$ http://boletimef.com.br/biblioteca/2592/artigo/BoletimEF.org_Indissociabilidadeentre-ensino-pesquisa-e-extensao.pdf > Acesso em: 20 de novembro de 2009.

DUMAZEDIER, J. 1979. Sociologia empírica do lazer. São Paulo: Perspectiva.

FACHIN, Odília. 2006. Fundamentos de metodologia. 5.ed. rev.atual. São Paulo: Saraiva.

FLICK, Uwe. 2009. Introdução à pesquisa qualitativa. 3.ed. Porto Alegre: Artmed.

GASTAL, Susana; MOESCH, Marutschka M. 2007. Turismo, políticas públicas e cidadania. São Paulo: Aleph.

GOMES, A. M. R.; FARIA, E. L. 2005. Lazer e diversidade cultural. Brasília: SESI/DN.

GOMES, C. 2010. O lazer como campo mobilizador de experiências interculturais revolucionárias e sua contribuição para uma educação transformadora. In: DALBEN, Ângela; DINIZ, Júlio; LEAL, Leiva; SANTOS, Lucíola (Orgs.). Convergências e tensões no campo da formação e do trabalho docente: Currículo, Ensino de Educação Física, Ensino de Geografia; Ensino de História; Escola, Família e Comunidade. Belo Horizonte: Autentica Editora. p. 284-310.

GOMES, C. L. 2009. O lazer como campo de atuação para profissionais da Educação Física: a questão das competências. In: Anais do XVI Congresso Brasileiro de Ciências do Esporte e III Congresso Internacional de Ciências do Esporte. Salvador. 
. 2008. Lazer, Trabalho e Educação: relações históricas, questões contemporâneas. 2. ed.(rev. ampl.). Belo Horizonte: Editora UFMG.

. (Org.). 2004. Dicionário Crítico do lazer. Belo Horizonte: Autêntica Editora.

ISAYAMA, H. F. 2002. Lazer e Educação Física: uma análise das disciplinas sobre recreação e lazer nos currículos dos cursos de Graduação em Educação Física. Campinas: Faculdade de Educação Física da Unicamp. (Tese, Doutorado em Educação Física)

$11-19$. 2005. Um olhar sobre a formação profissional em lazer. Licere. Belo Horizonte, v. 8, n.1, p.

MARCELLINO, Nelson C. 1987. Lazer e Educação. Campinas, SP: Papirus.

. 1996. Estudos do Lazer: uma introdução. Campinas, SP: autores associados.

. (Org.). 1995. Lazer: Formação e atuação profissional. Campinas: Papirus.

MELO, Victor A.; ALVES JUNIOR, Edmundo D. 2003. Introdução ao Lazer. Barueri, SP: Manole.

MORIN, Edgar.2007. Introdução ao pensamento complexo. 3.ed. Porto Alegre: Sulina.

SCHLUTER, Regina G. 2003. Metodologia da pesquisa em turismo e hotelaria. 2.ed. São Paulo: Aleph.

TRIBE, John. 2003. Economia do Lazer e do Turismo. São Paulo: Manole.

VALENTIM, Marta. 2007. Instrumentos integradores do ensino, pesquisa e extensão: o caso dos grupos de pesquisa. Revista teórica del Departamento de Ciencias de la Comunicación y de la Información Facultad de Humanidades - Universidad de Playa Ancha. Ano 3, Número 5. Disponível em: <http://web.upla.cl/revistafaro/02_monografico/pdf/05_monografico_valentim.pdf $>$ Acesso em: 20 de novembro de 2009.

WERNECK, C. L. G.; ISAYAMA, H. F. (Org.). 2003. Lazer, recreação e educação física. Belo Horizonte: Autêntica.

2001. O lazer no currículo dos cursos de graduação em Educação Física: Reflexões. Revista Cinergis. Santa Cruz do Sul, V.2, N.1, p.73-87. jan./jun.

Recebido em: 30/01/2010

Aprovado em: 07/07/2010 